\title{
The Role of Radionuclide Imaging in Epilepsy, Part 1: Sporadic Temporal and Extratemporal Lobe Epilepsy
}

\author{
Ajay Kumar and Harry T. Chugani \\ PET Center, Department of Pediatrics, Neurology, and Radiology, Children's Hospital of Michigan, Detroit Medical Center, Wayne \\ State University School of Medicine, Detroit, Michigan
}

\begin{abstract}
CE credit: For CE credit, you can access the test for this article, as well as additional JNMT CE tests, online at https://www.snmmilearningcenter.org. Complete the test online no later than March 2020. Your online test will be scored immediately. You may make 3 attempts to pass the test and must answer $80 \%$ of the questions correctly to receive $1.0 \mathrm{CEH}$ (Continuing Education Hour) credit. SNMMI members will have their CEH credit added to their VOICE transcript automatically; nonmembers will be able to print out a CE certificate upon successfully completing the test. The online test is free to SNMMI members; nonmembers must pay $\$ 15.00$ by credit card when logging onto the website to take the test.
\end{abstract}

Epilepsy is one of the most common yet diverse neurologic disorders, affecting almost $1 \%-2 \%$ of the population. Presently, radionuclide imaging such as PET and SPECT is not used in the primary diagnosis or evaluation of recent-onset epilepsy. However, it can play a unique and important role in certain specific situations, such as in noninvasive presurgical localization of epileptogenic brain regions in intractable-seizure patients being considered for epilepsy surgery. Radionuclide imaging can be particularly useful if MR imaging is either negative for lesions or shows several lesions of which only 1 or 2 are suspected to be epileptogenic and if electroencephalogram changes are equivocal or discordant with the structural imaging. Similarly, PET and SPECT can also be useful for evaluating the functional integrity of the rest of the brain and may provide useful information on the possible pathogenesis of the neurocognitive and behavioral abnormalities frequently observed in these patients.

Key Words: epilepsy; epilepsy syndromes; ${ }^{18} \mathrm{~F}-\mathrm{FDG}$; PET; radionuclide; epilepsy surgery; SPECT

J Nucl Med Technol 2017; 45:14-21

DOI: 10.2967/jnumed.112.114397

$\mathbf{P}$ resently, nuclear medicine imaging such as PET and SPECT is not used in the primary diagnosis or evaluation of recent-onset epilepsy. However, it can play a unique and important role in certain specific situations. Almost a fourth of epileptic patients do not respond to medical treatment and develop intractable seizures. PET and SPECT can play a significant role in such patients by its ability to

Received Apr. 22, 2013; revision accepted Aug. 6, 2013.

For correspondence or reprints contact: Ajay Kumar, Department of Pediatrics, Neurology, and Radiology, Wayne State University School of Medicine, PET Center, Children's Hospital of Michigan, Detroit, MI, 48201. E-mail: ajay@pet.wayne.edu

COPYRIGHT (C) 2017 by the Society of Nuclear Medicine and Molecular Imaging. noninvasively localize epileptogenic brain regions before surgery. PET and SPECT do not play much of a role in localization when structural lesions visible on MR imaging are concordant with electrophysiologic and clinical data. However, many patients may have no visible brain lesion on CT or MR imaging, particularly children less than 2 y old, in whom some cortical malformations may be poorly visualized or missed completely because of immature myelination and poor gray matter-white matter differentiation. This limitation is significant, considering that these abnormalities constitute a major cause of epilepsy in children. Similarly, patients may have multiple structural lesions of which only 1 or 2 are epileptogenic, may have seizures arising far from the lesion, or may have discordant or inconclusive electroencephalogram findings. PET and SPECT can be useful in such cases by identifying the epileptogenic regions and guiding the subsequent subdural-electrode placement and surgical resection. Sometimes the epileptogenic lesion may be medial and associated with generalized epileptiform activity rather than focal discharges on the electroencephalogram due to secondary bilateral synchrony. In such cases, PET or SPECT may allow for a surgical option in a patient who might otherwise not even be considered for surgery. In this review, we will discuss some important roles played by PET and SPECT in the presurgical evaluation of intractable seizures: for localizing epileptogenic regions, particularly when structural imaging results are normal, when there is discordance between structural and electrophysiologic data, and when multiple lesions are shown by other modalities; for identifying dual pathology; for assessing the presence of potential secondary epileptic foci; and for evaluating the functional integrity of the rest of the brain.

\section{RADIOTRACERS AND TECHNICAL CONSIDERATIONS}

Table 1 summarizes the PET and SPECT radiotracers used to evaluate epilepsy. 
TABLE 1

Targeted Pathways, Used Radiotracers, and Their Usual Uptake Pattern in Epileptogenic Region

\begin{tabular}{|c|c|c|}
\hline Target & Used radiotracers & Uptake pattern in epileptogenic region \\
\hline Blood perfusion & $\begin{array}{l}{ }^{15} \mathrm{O}-\mathrm{H}_{2} \mathrm{O},{ }^{99 m} \mathrm{Tc} \text {-ethyl cysteinate } \\
\text { dimer, }{ }^{99 m} \mathrm{Tc} \text {-hexamethyl } \\
\text { propyleneamine oxime }\end{array}$ & Interictal decrease; ictal increase \\
\hline \multicolumn{3}{|l|}{ Metabolic pathways } \\
\hline Glucose metabolism & ${ }^{18} \mathrm{~F}-\mathrm{FDG}$ & Interictal decrease ${ }^{\star}$; ictal increase \\
\hline Serotonin/kynurenine metabolism & ${ }^{11} \mathrm{C}-a-m e t h y l-\mathrm{L}-\operatorname{tryptophan}$ & Interictal increase \\
\hline Dopamine synthesis & ${ }^{18} \mathrm{~F}-\mathrm{L}_{-} \mathrm{DOPA}{ }^{\dagger}$ & Interictal decrease \\
\hline Monoamine oxidase & ${ }^{11} \mathrm{C}$-deuterium-deprenyl$\left.\right|^{\ddagger}$ & Interictal increase \\
\hline \multicolumn{3}{|l|}{ Receptors } \\
\hline Benzodiazepine & ${ }^{11} \mathrm{C}$-flumazenil ${ }^{\S}$ & \\
\hline Opiate & $\begin{array}{l}{ }^{11} \mathrm{C} \text {-carfentanill, }{ }^{18} \mathrm{~F} \text {-cyclofoxy }{ }^{\Uparrow} \text {, } \\
{ }^{11} \mathrm{C} \text {-diprenorphine }{ }^{\#},{ }^{11} \mathrm{C} \text {-methylnaltrindole }\end{array}$ & Interictal increase; interictal decrease \\
\hline 5-hydroxytryptamine & ${ }^{18} \mathrm{~F}-\mathrm{FCWAY}{ }^{\dagger \dagger},{ }^{11} \mathrm{C}-\mathrm{WAY}{ }^{\dagger \dagger},{ }^{18} \mathrm{~F}-\mathrm{MPPF}{ }^{\dagger \dagger}$ & Interictal decrease \\
\hline Dopamine & ${ }^{18} \mathrm{~F}$-fallypride ${ }^{\ddagger \ddagger},{ }^{11} \mathrm{C}-\mathrm{SCH} 23390^{\S \S}$ & Interictal decrease \\
\hline $\begin{array}{l}\text { Peripheral benzodiazepine } \\
\text { or translocator protein }\end{array}$ & ${ }^{11} \mathrm{C}-\mathrm{PK} 11195\|\|,{ }^{11} \mathrm{C}-\mathrm{PBR} 28\|\|$ & Interictal increase \\
\hline Histamine & ${ }^{11} \mathrm{C}$-doxepin 19 & Interictal increase \\
\hline$N$-methyl-D-aspartic acid & ${ }^{11} \mathrm{C}-$ ketamine $\# \#$ & Interictal decrease \\
\hline Acetylcholine & ${ }^{18} \mathrm{~F}-\mathrm{FA} 85380$ & Interictal decrease \\
\hline 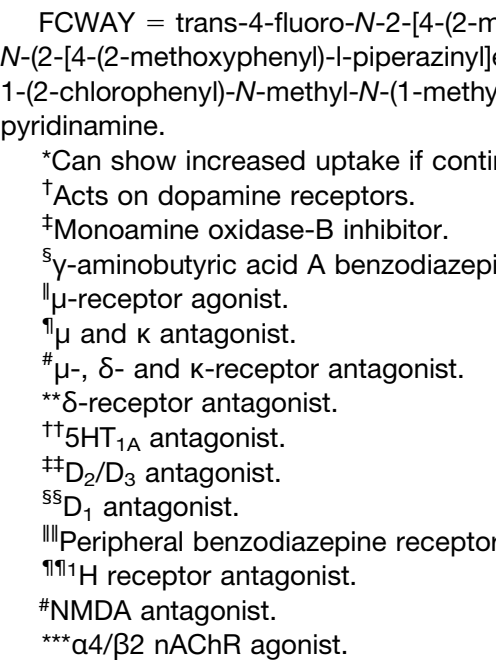 & $\begin{array}{l}\text { oxyphenyl) piperazin-1-yl] ethyl- } N-(2-\text { pyridyl) cy } \\
\text { l)- } N \text {-(2-pyridinyl)benzamide; L-DOPA }=\text { L-3,4-c } \\
\text { pyl)-3-isoquinoline carboxamide; PBR } 28=N \text { - } \\
\text { us spiking (interictal) or epileptiform discharges }\end{array}$ & $\begin{array}{l}\text { hexanecarboxamide; MPPF }=4-{ }^{18} \text { F-fluoro } \\
\text { droxyphenylalanine (levodopa); PK11195 } \\
\text { tyl- } N-\left(2-\left[{ }^{11} \mathrm{C}-\text { methoxybenzyl)-2-phenoxy-5 }\right.\right. \\
\text { al). }\end{array}$ \\
\hline
\end{tabular}

\section{PET Imaging}

The most commonly used PET tracer in epilepsy is ${ }^{18} \mathrm{~F}-\mathrm{FDG}$, which measures glucose metabolism related to the synaptic and neuronal activity of the brain tissue (1). Interictal ${ }^{18}$ F-FDG PET typically shows reduced radiotracer uptake (hypometabolism) in the epileptogenic region (Fig. 1). This hypometabolism can result from a variety of mechanisms, including neuronal loss, diaschisis, or reduction in synaptic density. It appears that cortical hypometabolism may be associated with the duration, frequency, and severity of the seizures, as hypometabolism is usually found in only $25 \%$ of children with new-onset epilepsy, compared with $80 \%-85 \%$ of adults with intractable seizures (2). Persistent or increased seizure frequency may lead to enlargement of the hypometabolic area, whereas reduced seizure frequency may be associated with a decrease in the size of the hypometabolic cortex or even resolution of the hypometabolism
(3). Hypometabolism of the ipsilateral thalamus can be seen in cases of focal epilepsy (mostly in the frontal and temporal cortex, medial temporal lobe epilepsy being particularly associated with dorsal thalamus hypometabolism; Fig. 1). Contralateral cerebellar hypometabolism (diaschisis) can be seen in cases of frontal (mainly) or parietal lobe seizures (Fig. 1). Occasionally, hypometabolism is seen in a contralateral mirror region and represents functional suppression of these regions through callosal fibers (transcallosal diaschisis) or through the fornix if the hippocampus is contralateral. Longstanding uncontrolled seizures may show extensive areas of hypometabolism, likely involving seizure propagation pathways or indicating the effect of the seizures on connected brain regions. Another factor that can affect the rate of glucose metabolism in the brain is the use of antiepileptic drugs. The absolute rates of glucose metabolism can be decreased by these drugs (such as barbiturates, valproate, phenytoin, or 
carbamazepine; the decrease is greatest with barbiturates and less with the 3 other drugs, in the order listed) (4).

Because ${ }^{18}$ F-FDG PET usually shows a large area of hypometabolism extending beyond the epileptogenic region, this modality cannot reliably be used to precisely determine the surgical margin. However, it can be used for lateralization and general localization of the seizure focus. This information can help in making an a priori hypothesis about subsequent subdural electrode placementinformation that may be useful, particularly when the results of MR imaging are normal. At the same time, ${ }^{18} \mathrm{~F}-$ FDG PET can be useful for evaluating the functional status of the rest of the brain when an epileptogenic lesion is considered for surgical resection, as postsurgical neurocognitive outcome will also depend on the integrity of the remaining (unresected) cortex. Such an evaluation is particularly important in children, because brain plasticity after resection is likely to involve functionally intact regions.

For clinical ${ }^{18}$ F-FDG images, visual inspection is the standard method of interpretation, with the interpreter comparing any hemispheric asymmetry with a normal ${ }^{18} \mathrm{~F}-\mathrm{FDG}$ brain pattern. The analysis can be further refined by calculating the asymmetry index and comparing it with a preselected threshold value of asymmetry (usually $\sim 10 \%$ ) to aid surgical resection of epileptic foci (5). Various other methods of PET data analysis, such as statistical parametric mapping (SPM, a voxel-based whole-brain analysis) or SPM extent analysis with asymmetry index, can also be used and can either increase the diagnostic yield of the PET scan or be helpful in equivocal cases (Fig. 2) (6-8).

Another PET tracer with the potential for detecting epileptic brain regions is ${ }^{11} \mathrm{C}$-flumazenil, which binds to $\alpha$ subunits of the $\gamma$-aminobutyric acid A benzodiazepine receptor. ${ }^{11} \mathrm{C}$-flumazenil binding in the medial temporal lobe is robust enough for its good visualization (compared with ${ }^{18} \mathrm{~F}$-FDG PET, with which the medial temporal region, particularly the hippocampus, is often not well visualized). This characteristic of ${ }^{11} \mathrm{C}$-flumazenil PET is a main reason that it is preferred over ${ }^{18} \mathrm{~F}$-FDG PET for use in medial

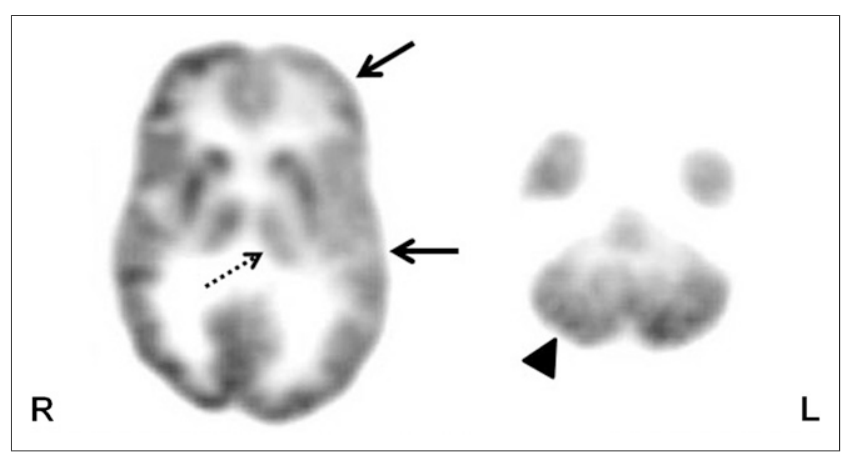

FIGURE 1. Axial ${ }^{18} \mathrm{~F}-\mathrm{FDG}$ PET scan in patient with intractable epilepsy, showing hypometabolism in left frontotemporal cortex (solid arrows). Also seen is hypometabolism in ipsilateral thalamus (broken arrow) and contralateral cerebellum (arrowhead), likely representing thalamic and cerebellar diaschisis, respectively. temporal lobe epilepsy, with the former showing focally decreased tracer binding in the hippocampus, compared with the larger area of hypometabolism also involving the temporal neocortex shown by the latter (Fig. 3). Also evaluated in epilepsy have been various other radioligands that bind to translocator protein (previously known as peripheral benzodiazepine receptors and expressed on activated microglia in cases of neuroinflammation), opioid receptors, histamine receptors, $N$-methyl-D-aspartate (NMDA) receptors, serotonin receptors, and acetylcholine receptors. Among these radioligands, ${ }^{11} \mathrm{C}-\alpha$-methyl-L-tryptophan, which does not bind to a receptor but measures tryptophan metabolism, appears to be a promising candidate. Interestingly, PET performed with this radioligand can show increased uptake in the epileptogenic cortex interictally, making visual detection easier than with those tracers whose uptake or binding is usually reduced in the interictal phase (9).

\section{SPECT Imaging}

In epilepsy, SPECT imaging is used mostly to provide information about cerebral perfusion, alteration of which is considered to depend on the electrical status of the brain. The most common radiotracers used for this purpose are hexamethylpropyleneamine oxime and ethyl cysteinate dimer labeled with ${ }^{99 \mathrm{~m}} \mathrm{Tc}$. During a seizure, the cerebral blood flow changes rapidly over time, depending on the type of seizure and its mode of propagation. Therefore, early injection of the radiotracer during the seizure is imperative to capture blood flow changes in the epileptic zone. Similarly, knowledge of the exact time of injection and duration of the seizure is important for correct interpretation of the SPECT images. Delayed injection of radiotracer may show a variable pattern of blood flow changes in the epileptic zone as the seizure evolves, as well as a variation in the mode and pattern of seizure propagation.

During the ictal phase, blood flow in the epileptic region can increase by up to $300 \%$ and can be seen as an area of hyperperfusion on ictal SPECT (Fig. 4) (10). True ictal SPECT (tracer injected immediately after the onset of the seizure and SPECT images showing perfusion at that time) shows an area of hyperperfusion in the epileptogenic region, surrounded by an area of hypoperfusion that becomes more prominent at the end of the ictal phase. This surrounding area of hypoperfusion may be caused by the steal syndrome (shifting of blood flow to the seizure focus) or may reflect an inhibitory zone trying to limit the seizure spread (11). Interictal SPECT (tracer injected when the patient is not having any clinical or subclinical seizure and SPECT images showing the baseline perfusion pattern) shows hypoperfusion or normal perfusion in the epileptogenic region (Fig. 4). Even when present, hypoperfusion may be mild and sometimes difficult to distinguish from the surrounding normal brain on visual examination. The main role of interictal SPECT at present is to assist in the evaluation of ictal SPECT, visually or quantitatively, using SPM or SISCOM (subtraction ictal SPECT coregistered to MR imaging; that 


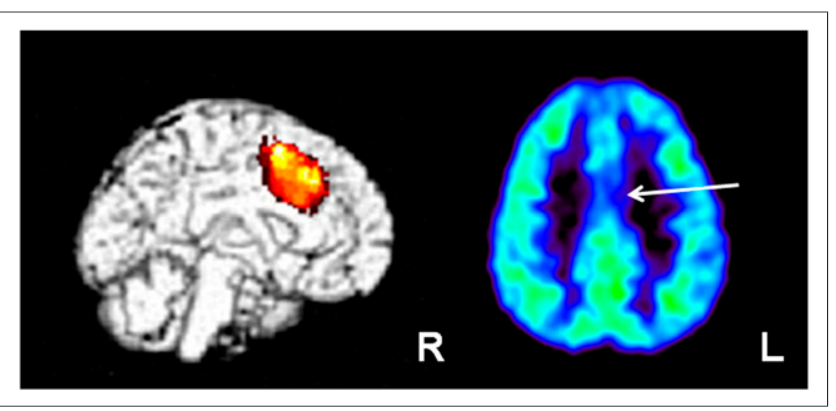

FIGURE 2. SPM analysis of ${ }^{18}$ F-FDG PET scan in child with intractable epilepsy, normal findings on MR imaging, and generalized electroencephalogram changes. Initial reading showed normal findings on ${ }^{18} \mathrm{~F}-\mathrm{FDG}$ PET; however, SPM analysis revealed area of hypometabolism in left medial frontal/ cingulate cortex (left image), which appeared to be suggestive/ hypometabolic in rereview of ${ }^{18} \mathrm{~F}-\mathrm{FDG}$ PET scan (arrow; right image). Child underwent 2-stage epilepsy surgery with intracranial subdural interhemispheric electrode placement, which showed ictal discharges from this region. These medial discharges perhaps resulted in generalized (nonlateralized) electroencephalogram changes. Area was resected and child is seizure-free after surgery.

is, the interictal SPECT images are subtracted from the ictal images and the results are displayed on coregistered MR images), by providing a baseline blood flow. Use of these registration techniques can increase the sensitivity and specificity of ictal SPECT $(12,13)$. The probability of localizing an ictal onset zone has been found to be higher with SISCOM than with ictal electroencephalography and MR imaging (14). Use of SISCOM can help in revisiting and detecting subtle changes on MR images that were initially reported as showing normal findings (15). Studies have shown that the area of the resected SISCOM abnormality is associated with surgical outcome; the larger the area of the resected SISCOM abnormality, the better the outcome $(14,16)$. However, the use of SPECT or SISCOM in children can sometimes be limited by the difficulty of acquiring good interictal or ictal

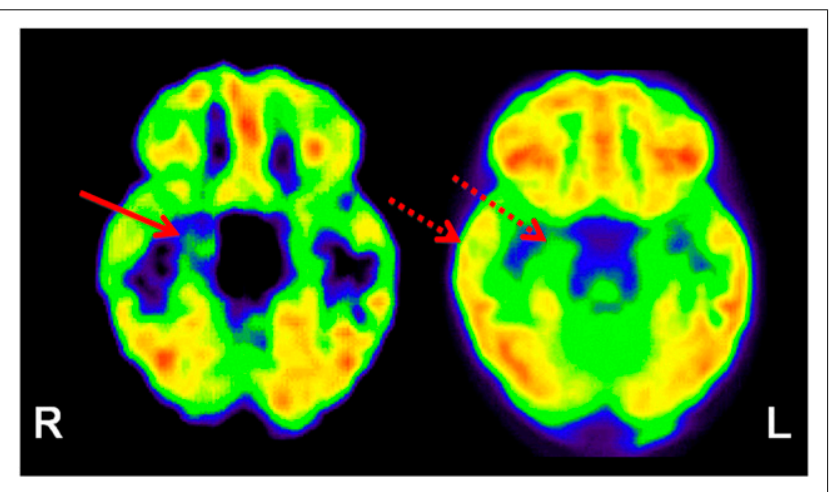

FIGURE 3. ${ }^{11} \mathrm{C}$-flumazenil PET (left image) showing focal abnormality (decreased tracer binding) involving right hippocampus (solid arrow) in patient with medial temporal lobe epilepsy. In comparison, ${ }^{18} \mathrm{~F}-\mathrm{FDG}$ PET (right image) shows widespread ${ }^{18} \mathrm{~F}-\mathrm{FDG}$ hypometabolism in right temporal lobe, including neocortex (broken arrows). brain SPECT images, as seizures in children may be frequent and brief (such as infantile spasms or myoclonic epilepsy).

\section{TEMPORAL AND EXTRATEMPORAL LOBE EPILEPSY}

\section{PET Imaging}

${ }^{18}$ F-FDG PET has a reported sensitivity of $85 \%-90 \%$ in detection of the epileptic brain region in cases of temporal lobe epilepsy $(17-19) .{ }^{18} \mathrm{~F}-\mathrm{FDG}$ PET can help to identify the epileptic temporal lobe in almost half of patients with noncontributory electroencephalography (20). However, temporal lobe interictal hypometabolic regions often extend beyond the presumed epileptogenic zone. The temporal neocortex is probably involved in most patients with medial temporal lobe epilepsy, and it is difficult to distinguish medial from lateral temporal lobe epilepsy on the basis of ${ }^{18}$ F-FDG PET patterns $(21,22)$. Patients may show hypometabolism in the ipsilateral parietal and frontal cortex, in the thalamus, and even occasionally in the contralateral temporal lobe (23). This pattern may represent the epileptic network involved in seizure propagation (24) and be related to the behavioral and neuropsychologic changes of chronic epilepsy. ${ }^{18}$ F-FDG PET can be particularly helpful in dualpathology cases (coexistence of medial temporal and neocortical seizure foci) or when a secondary noncontiguous epileptic focus due to kindling or similar effects is suspected. In cases of extratemporal epilepsy, ${ }^{18} \mathrm{~F}$-FDG PET does not perform as well, with a reported sensitivity of $45 \%-92 \%$ (generally $\sim 55 \%$ ) in localizing the epileptogenic zone in frontal lobe epilepsy (25-27). Poor localization for ${ }^{18} \mathrm{~F}-\mathrm{FDG}$ PET has also been reported in cases of occipital lobe epilepsy (28). However, considering that the incidence of extratemporal epilepsy is higher in children and that most have normal MR imaging findings, ${ }^{18} \mathrm{~F}-$ FDG PET can be useful for clinical management in the pediatric population. ${ }^{18} \mathrm{~F}$-FDG PET can be particularly useful in cortical dysplasia, which appears to be a major etiology for pediatric epilepsy, unlike adult epilepsy, for which hippocampal sclerosis is a major etiology. ${ }^{18}$ F-FDG PET can also sometimes detect, and thus provide an opportunity for surgical treatment of, heterotopias, which often lead to intractable epilepsy and may be subtle enough to escape detection by MR imaging (Fig. 5).

${ }^{18}$ F-FDG PET can provide additional information about the epileptic focus in up to two thirds of cases, affecting surgical decision making in up to $50 \%-70 \%$ of cases and sometimes changing initial decisions based on MR imaging or electroencephalography $(29,30)$. Further, ${ }^{18}$ F-FDG PET alone may be the basis for surgical decisions in almost $17 \%$ of patients (30). ${ }^{18} \mathrm{~F}$-FDG PET has been found to be most useful when MR imaging findings are negative or when ictal electroencephalography is discordant with MR imaging or seizure semiology (30). ${ }^{18} \mathrm{~F}$-FDG PET findings can also predict surgical outcome, as ipsilateral PET hypometabolism appears to be associated with a good outcome $(86 \%)$ even in patients with negative MR imaging findings (80\%) or with noncontributory ictal scalp electroencephalography 


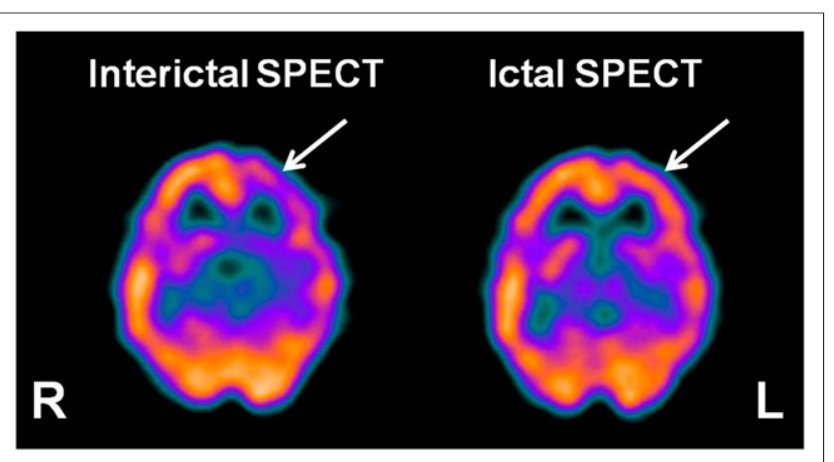

FIGURE 4. Interictal 99mTc-ethyl cysteinate dimer SPECT (left image) showing the usual hypoperfusion in presumed epileptogenic focus (arrow) in left frontal cortex region, which becomes hyperperfused during ictal SPECT (right image).

(72\%) (31). An odds ratio of 7 has been reported for ${ }^{18} \mathrm{~F}-$ FDG PET in predicting a seizure-free outcome after epilepsy surgery (32), though it is difficult to predict who will not become seizure-free after surgery (33). In one study, patients with more severe temporal lobe hypometabolism appeared to have better postsurgical seizure control (34). However, in another study, no association was found between surgical outcome and the results of ${ }^{18}$ F-FDG PET along with MR imaging, electroencephalography, or ictal SPECT (35). The basis for these differences is not entirely clear, but they may be related to confounders such as differences in the patient populations, in the resolutions of the scanners, and in the approaches to image analysis. Medial temporal compared with lateral temporal hypometabolism (36), restricted temporal hypometabolism (37), and greater inferior lateral temporal hypometabolism (20) appear to be independent predictors for seizure control in temporal lobe epilepsy. Contralateral hypometabolism is a negative prognostic factor (38).

Additionally, ${ }^{18} \mathrm{~F}-\mathrm{FDG}$ PET can provide some other important prognostic information. For example, in patients with unilateral temporal lobe epilepsy, the presence of bitemporal glucose hypometabolism is associated with poor memory performance (39) and prefrontal hypometabolism is associated with impaired executive function (40). Similarly, associated hypometabolism of the ipsilateral insular cortex may correlate with emotional or somesthetic symptoms (41). Bilateral lateral temporal and bilateral medial

FIGURE 5. Axial ${ }^{18} \mathrm{~F}-\mathrm{FDG}$ PET scan showing subcortical band heterotopia (arrows) in right temporal-occipital white matter in child with intractable epilepsy and normal MR imaging findings. Heterotopic band has higher glucose uptake than adjacent white matter but lower uptake than cortex. prefrontal hypometabolism may be associated with interictal aggressive behavior, probably because of removal of the inhibitory effects of the temporal neocortex (and perhaps the medial prefrontal cortex) on the medial temporal lobe (42). Thalamic glucose metabolism can be an independent predictor of surgical outcome in patients with temporal lobe epilepsy, with thalamic hypometabolism contralateral to the epileptic foci relating to poor surgical outcome, compared with ipsilateral or no thalamic hypometabolism (43).

Under specific circumstances, some other radiotracers can be more useful than ${ }^{18} \mathrm{~F}-\mathrm{FDG}$ for evaluating epilepsy. For example, ${ }^{11} \mathrm{C}$-flumazenil may sometimes show a smaller area of abnormality than does ${ }^{18} \mathrm{~F}$-FDG PET $(19,44) .{ }^{11} \mathrm{C}-$ flumazenil PET is sensitive in temporal lobe epilepsy (19), particularly in cases of a sclerotic hippocampus (45). ${ }^{11} \mathrm{C}$-flumazenil PET has been reported to have a sensitivity of up to $100 \%$ in the detection of unilateral hippocampal sclerosis, with contralateral abnormalities detected in a third of patients with apparently unilateral hippocampal sclerosis $(45,46)$. In MR imaging-negative temporal lobe epilepsy, ${ }^{11} \mathrm{C}$ flumazenil PET results have been found to be abnormal in up to $85 \%$ of patients (47). In cases of extratemporal lobe epilepsy, ${ }^{11} \mathrm{C}$-flumazenil PET has been shown to have a sensitivity of 60\%-100\% for detecting the epileptogenic cortex using intracranial ictal electroencephalography as the gold standard $(19,48,49)$, and complete resection of the ${ }^{11} \mathrm{C}$-flumazenil abnormality has been found to be associated with good seizure outcome, even in children with normal MR imaging results $(48,50)$. Contrary to ${ }^{18} \mathrm{~F}-\mathrm{FDG}$ PET, which usually shows extratemporal hypometabolism in the parietal and frontal cortex in cases of temporal lobe epilepsy (probably associated with cognitive dysfunction or reflecting diaschisis), decreased ${ }^{11} \mathrm{C}$-flumazenil binding usually represents neuronal loss or receptor changes related to epileptogenicity and therefore should be more closely scrutinized (46). Use of SPM can further increase the accuracy of ${ }^{11} \mathrm{C}$-flumazenil PET, allowing detection of subtle changes in ${ }^{11} \mathrm{C}$-flumazenil binding that are difficult to appreciate visually $(41,45)$. These SPM studies sometimes have also found increased ${ }^{11} \mathrm{C}$-flumazenil binding, which in some cases has indicated cortical developmental malformations (51). Also, in normal-appearing temporal lobe white matter, the use of SPM has revealed increased ${ }^{11} \mathrm{C}$ flumazenil binding that was found, on histopathologic examination, to be caused by microdysgenesis (52). This is an interesting finding, as these ectopic neuronal clusters may lead to epileptogenesis by providing an aberrant circuitry.

Several other PET tracers, such as those evaluating tryptophan metabolism or receptors for opiate, histamine, NMDA, acetylcholine, dopamine, and other neurotransmitters, have been developed and used in epilepsy (Table 1). One study found ${ }^{11} \mathrm{C}-\alpha$-methyl-L-tryptophan PET to be useful in patients with temporal lobe epilepsy and a normal hippocampal volume (53). This tracer appears to be especially useful in cases of cortical dysplasia with normal MR imaging findings and mild ${ }^{18} \mathrm{~F}-\mathrm{FDG}$ changes. In such cases, the tracer sometimes shows increased uptake, particularly 

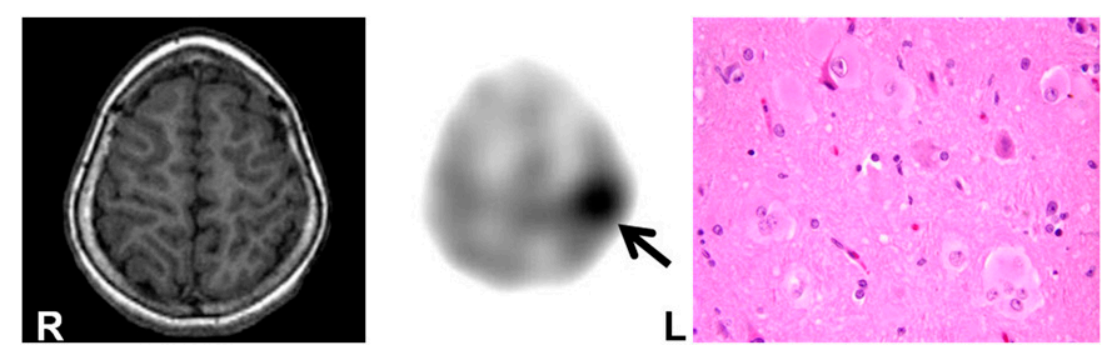

FIGURE 6. ${ }^{11} \mathrm{C}$-a-methyl-L-tryptophan PET scan (middle image) showing increased tracer uptake in left parietal lobe (arrow) in child with intractable epilepsy and normal findings on MR imaging (left image). Postsurgical histopathology (right image) revealed type IIB cortical dysplasia with balloon cells $(\times 40$, hematoxylin and eosin). Child remains seizure-free after epilepsy surgery.

in patients with cortical dysplasia type IIB, who usually have a good surgical outcome (Fig. 6) (54). This is an important development, as it indicates that there appears to be an in vivo imaging technique that can predict pathologic subtype and thus may provide presurgical prognostic information. Studies of opiate receptor PET imaging have reported both increased (55) and normal (56) receptor density in patients with temporal lobe epilepsy, whereas lower receptor availability was reported in the left parietotemporooccipital cortex in patients with reading epilepsy (57). Available data suggest that there is endogenous opioid release during the ictal phase, resulting in reduced receptor availability and reduced tracer binding, followed by low levels of endogenous opioids, resulting in increased receptor availability and therefore increased tracer binding. Similarly, the level of monoamine oxidase B has been found to be both high (58) and low (59) in temporal lobe epilepsy. Although significantly reduced dopamine receptor binding has been reported in the epileptogenic temporal lobe in temporal lobe epilepsy (60), no binding alterations were found with PET using ${ }^{11} \mathrm{C}$-verapamil, a p-glycoprotein substrate (61). Patients with temporal lobe epilepsy have also been found to have reduced NMDA receptor binding (62) but increased ${ }^{11} \mathrm{C}$-doxepine uptake (63) in the ipsilateral temporal cortex. Although one group found reduced dopamine-1 receptor binding in the right putamen in autosomal dominant nocturnal frontal lobe epilepsy (64), another group found increased tracer binding to nicotinic acetylcholine receptors in the midbrain, pons, and cerebellum and reduced binding in the dorsolateral prefrontal cortex in this condition (65). Recently, evidence of inflammatory changes was shown using ${ }^{11} \mathrm{C}$-PBR28 ( $N$-acetyl- $N-\left(2-{ }^{11} \mathrm{C}\right.$-methoxy-

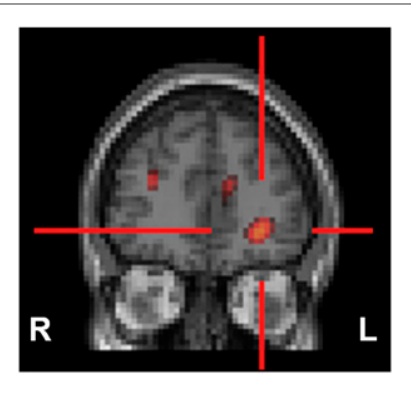

FIGURE 7. SISCOM may result in better delineation of epileptogenic focus, which may sometimes be missed even on ictal SPECT. In child with intractable complex partial epilepsy with normal findings on MR imaging and nonlocalizing scalp electroencephalography, SISCOM revealed focus of hyperperfusion in left inferior frontal cortex (red cross), likely representing seizure focus. benzyl)-2-phenoxy-5-pyridinamine), a marker of activated microglia-mediated neuroinflammation, in the hippocampus, parahippocampal gyrus, amygdala, and fusiform gyrus ipsilateral to the epileptic focus in patients with temporal lobe epilepsy (66). Although this is a preliminary finding and it is not clear whether observed neuroinflammatory changes are the cause or the effect of seizures, these observations are quite interesting and encouraging. However, there have not been many studies involving these tracers, and there has been no class I evidence; furthermore, the findings have been mixed and variable. In addition, most of these studies come from only a handful of centers. Therefore, more data are required before a valid conclusion can be reached about the usefulness of the findings in epilepsy evaluation.

\section{SPECT Imaging}

SPECT can reveal focal perfusion abnormalities concordant with other noninvasive presurgical examinations in up to $95 \%$ of patients $(14,15,67-69)$. However, the overall sensitivity for interictal SPECT is low $(<50 \%)$ for the detection of epileptogenic regions in temporal lobe epilepsy, with false-positive or false-negative findings in $20 \%-75 \%$ of cases. In contrast, ictal SPECT can correctly localize the epileptogenic focus in $70 \%-90 \%$ of cases with unilateral temporal lobe epilepsy $(68,70-72)$. False localization is usually due to rapid seizure propagation or subclinical seizure onset. In addition, resection of the SPECT focus has been found to be associated with a favorable surgical outcome (67). The use of SISCOM can increase the focus detection rate by up to $93 \%$, compared with $74 \%$ without it (Fig. 7) (73). The sensitivity of postictal SPECT (70\%-90\%) has also been reported to be greater than that of interictal SPECT and can further improve with use of SISCOM (74). However, in extra-temporal lobe epilepsy, SPECT may not be as useful, as seizures are brief and propagate rapidly, thus making it difficult to acquire an ictal SPECT study, and a much lower sensitivity $(66 \%)$ has been reported for ictal SPECT (75). Interestingly, in 2 studies, ictal SPECT or SISCOM was found to be more sensitive than ${ }^{18} \mathrm{~F}-\mathrm{FDG}$ PET in the detection of epileptic foci $(76,77)$. However, in another study of occipital lobe epilepsy, ictal hexamethylpropyleneamine oxime SPECT was found to be less sensitive than ${ }^{18} \mathrm{~F}-\mathrm{FDG}$ PET (78). SISCOM appears to increase the diagnostic yield in extra-temporal lobe epilepsy patients also and correlates better with postsurgical outcome $(16,32)$. 


\section{CONCLUSION}

Radionuclide imaging such as PET and SPECT can play an important role in noninvasive presurgical localization of epileptogenic brain regions in patients with intractable seizures who are being considered for epilepsy surgery. Radionuclide imaging may be particularly useful if MR imaging findings are negative or show multifocal lesions of which only 1 or 2 are suspected to be epileptogenic and if electroencephalogram changes are equivocal or discordant with the structural imaging. PET and SPECT can be helpful in evaluating the functional integrity of the rest of the brain and may provide useful information on the possible pathogenesis of the observed neurocognitive and behavioral abnormalities.

\section{REFERENCES}

1. Rocher AB, Chapon F, Blaizot X, Baron JC, Chavoix C. Resting-state brain glucose utilization as measured by PET is directly related to regional synaptophysin levels: a study in baboons. Neuroimage. 2003;20:1894-1898.

2. Gaillard WD, Kopylev L, Weinstein S, et al. Low incidence of abnormal ${ }^{18}$ FDGPET in children with new-onset partial epilepsy: a prospective study. Neurology. 2002;58:717-722.

3. Benedek K, Juhasz C, Chugani DC, Muzik O, Chugani HT. Longitudinal changes in cortical glucose hypometabolism in children with intractable epilepsy. J Child Neurol. 2006;21:26-31.

4. Theodore WH. Antiepileptic drugs and cerebral glucose metabolism. Epilepsia. 1988;29(suppl 2):S48-S55

5. Muzik O, Chugani DC, Shen C, et al. Objective method for localization of cortical asymmetries using positron emission tomography to aid surgical resection of epileptic foci. Comput Aided Surg. 1998;3:74-82

6. Kim MA, Heo K, Choo MK, et al. Relationship between bilateral temporal hypometabolism and EEG findings for mesial temporal lobe epilepsy: analysis of ${ }^{18}$ F-FDG PET using SPM. Seizure. 2006;15:56-63.

7. Kumar A, Juhasz C, Asano E, Sood S, Muzik O, Chugani HT. Objective detection of epileptic foci by ${ }^{18} \mathrm{~F}$-FDG PET in children undergoing epilepsy surgery. J Nucl Med. 2010;51:1901-1907.

8. Van Bogaert P, Massager N, Tugendhaft P, et al. Statistical parametric mapping of regional glucose metabolism in mesial temporal lobe epilepsy. Neuroimage. 2000;12:129-138.

9. Kumar A, Asano E, Chugani HT. alpha- $\left[{ }^{11} \mathrm{C}\right]$-methyl-L-tryptophan PET for tracer localization of epileptogenic brain regions: clinical studies. Biomark Med. 2011;5:577-584.

10. Hougaard K, Oikawa T, Sveinsdottir E, Skinoj E, Ingvar DH, Lassen NA. Regional cerebral blood flow in focal cortical epilepsy. Arch Neurol. 1976;33:527535.

11. Prince DA, Wilder BJ. Control mechanisms in cortical epileptogenic foci: "surround" inhibition. Arch Neurol. 1967;16:194-202.

12. Bruggemann JM, Som SS, Lawson JA, Haindl W, Cunningham AM, Bye AM. Application of statistical parametric mapping to SPET in the assessment of intractable childhood epilepsy. Eur J Nucl Med Mol Imaging. 2004;31:369-377.

13. Lee JD, Kim HJ, Lee BI, Kim OJ, Jeon TJ, Kim MJ. Evaluation of ictal brain SPET using statistical parametric mapping in temporal lobe epilepsy. Eur J Nucl Med. 2000;27:1658-1665.

14. O'Brien TJ, So EL, Mullan BP, et al. Subtraction ictal SPECT co-registered to MRI improves clinical usefulness of SPECT in localizing the surgical seizure focus. Neurology. 1998;50:445-454.

15. Chiron C, Vera P, Kaminska A, et al. Single-photon emission computed tomography: ictal perfusion in childhood epilepsies. Brain Dev. 1999;21:444-446.

16. O'Brien TJ, So EL, Mullan BP, et al. Subtraction peri-ictal SPECT is predictive of extratemporal epilepsy surgery outcome. Neurology. 2000;55:16681677.

17. Gaillard WD, Bhatia S, Bookheimer SY, Fazilat S, Sato S, Theodore WH. FDGPET and volumetric MRI in the evaluation of patients with partial epilepsy. Neurology. 1995;45:123-126.

18. Knowlton RC, Laxer KD, Ende G, et al. Presurgical multimodality neuroimaging in electroencephalographic lateralized temporal lobe epilepsy. Ann Neurol. 1997;42:829-837.
19. Ryvlin P, Bouvard S, Le Bars D, et al. Clinical utility of flumazenil-PET versus $\left[{ }^{18} \mathrm{~F}\right]$ fluorodeoxyglucose-PET and MRI in refractory partial epilepsy: a prospective study in 100 patients. Brain. 1998;121:2067-2081.

20. Theodore WH, Sato S, Kufta CV, Gaillard WD, Kelley K. FDG-positron emission tomography and invasive EEG: seizure focus detection and surgical outcome. Epilepsia. 1997;38:81-86.

21. Hajek M, Antonini A, Leenders KL, Wieser HG. Mesiobasal versus lateral temporal lobe epilepsy: metabolic differences in the temporal lobe shown by interictal ${ }^{18} \mathrm{~F}$-FDG positron emission tomography. Neurology. 1993;43:7986.

22. Kim YK, Lee DS, Lee SK, et al. Differential features of metabolic abnormalities between medial and lateral temporal lobe epilepsy: quantitative analysis of ${ }^{18} \mathrm{~F}$ FDG PET using SPM. J Nucl Med. 2003;44:1006-1012.

23. Henry TR, Mazziotta JC, Engel J Jr. Interictal metabolic anatomy of mesial temporal lobe epilepsy. Arch Neurol. 1993;50:582-589.

24. Chassoux F, Semah F, Bouilleret V, et al. Metabolic changes and electro-clinical patterns in mesio-temporal lobe epilepsy: a correlative study. Brain. 2004;127: 164-174.

25. da Silva EA, Chugani DC, Muzik O, Chugani HT. Identification of frontal lobe epileptic foci in children using positron emission tomography. Epilepsia. 1997;38:1198-1208.

26. Kim YK, Lee DS, Lee SK, Chung CK, Chung JK, Lee MC. ${ }^{18}$ F-FDG PET in localization of frontal lobe epilepsy: comparison of visual and SPM analysis. $J$ Nucl Med. 2002;43:1167-1174.

27. Swartz BW, Khonsari A, Vrown C, Mandelkern M, Simpkins F, Krisdakumtorn T. Improved sensitivity of ${ }^{18}$ FDG-positron emission tomography scans in frontal and "frontal plus" epilepsy. Epilepsia. 1995;36:388-395.

28. Patil S, Biassoni L, Borgwardt L. Nuclear medicine in pediatric neurology and neurosurgery: epilepsy and brain tumors. Semin Nucl Med. 2007;37:357-381.

29. Ollenberger GP, Byrne AJ, Berlangieri SU, et al. Assessment of the role of FDG PET in the diagnosis and management of children with refractory epilepsy. Eur $J$ Nucl Med Mol Imaging. 2005;32:1311-1316.

30. Uijl SG, Leijten FS, Arends JB, Parra J, van Huffelen AC, Moons KG. The added value of $\left[{ }^{18} \mathrm{~F}\right]$-fluoro-D-deoxyglucose positron emission tomography in screening for temporal lobe epilepsy surgery. Epilepsia. 2007;48:2121-2129.

31. Willmann O, Wennberg R, May T, Woermann FG, Pohlmann-Eden B. The contribution of ${ }^{18} \mathrm{~F}$-FDG PET in preoperative epilepsy surgery evaluation for patients with temporal lobe epilepsy: a meta-analysis. Seizure. 2007;16:509-520.

32. Knowlton RC, Elgavish RA, Bartolucci A, et al. Functional imaging: II. Prediction of epilepsy surgery outcome. Ann Neurol. 2008;64:35-41.

33. Uijl SG, Leijten FS, Arends JB, Parra J, van Huffelen AC, Moons KG. Prognosis after temporal lobe epilepsy surgery: the value of combining predictors. Epilepsia. 2008;49:1317-1323.

34. Theodore WH, Sato S, Kufta C, Balish MB, Bromfield EB, Leiderman DB. Temporal lobectomy for uncontrolled seizures: the role of positron emission tomography. Ann Neurol. 1992;32:789-794.

35. Kim DW, Lee SK, Chu K, et al. Predictors of surgical outcome and pathologic considerations in focal cortical dysplasia. Neurology. 2009;72:211-216.

36. Delbeke D, Lawrence SK, Abou-Khalil BW, Blumenkopf B, Kessler RM. Postsurgical outcome of patients with uncontrolled complex partial seizures and temporal lobe hypometabolism on ${ }^{18}$ FDG-positron emission tomography. Invest Radiol. 1996;31:261-266.

37. Manno EM, Sperling MR, Ding X, et al. Predictors of outcome after anterior temporal lobectomy: positron emission tomography. Neurology. 1994;44:23312336.

38. Wong $\mathrm{CH}$, Bleasel A, Wen $\mathrm{L}$, et al. The topography and significance of extratemporal hypometabolism in refractory mesial temporal lobe epilepsy examined by FDG-PET. Epilepsia. 2010;51:1365-1373.

39. Koutroumanidis M, Hennessy MJ, Seed PT, et al. Significance of interictal bilateral temporal hypometabolism in temporal lobe epilepsy. Neurology. 2000;54:18111821 .

40. Jokeit H, Seitz RJ, Markowitsch HJ, Neumann N, Witte OW, Ebner A. Prefrontal asymmetric interictal glucose hypometabolism and cognitive impairment in patients with temporal lobe epilepsy. Brain. 1997;120:2283-2294.

41. Bouilleret V, Dupont S, Spelle L, Baulac M, Samson Y, Semah F. Insular cortex involvement in mesiotemporal lobe epilepsy: a positron emission tomography study. Ann Neurol. 2002;51:202-208.

42. Juhász C, Behen ME, Muzik O, Chugani DC, Chugani HT. Bilateral medial prefrontal and temporal neocortical hypometabolism in children with epilepsy and aggression. Epilepsia. 2001;42:991-1001.

43. Newberg AB, Alavi A, Berlin J, Mozley PD, O'Connor M, Sperling M. Ipsilateral and contralateral thalamic hypometabolism as a predictor of outcome after temporal lobectomy for seizures. J Nucl Med. 2000;41:1964-1968. 
44. Savic I, Ingvar M, Stone-Elander S. Comparison of $\left[{ }^{11} \mathrm{C}\right]$ flumazenil and $\left[{ }^{18} \mathrm{~F}\right]$ FDG as PET markers of epileptic foci. J Neurol Neurosurg Psychiatry. 1993;56:615-621.

45. Koepp MJ, Richardson MP, Brooks DJ, et al. Cerebral benzodiazepine receptors in hippocampal sclerosis: an objective in vivo analysis. Brain. 1996;119:16771687.

46. Henry TR, Frey KA, Sackellares JC, et al. In vivo cerebral metabolism and central benzodiazepine-receptor binding in temporal lobe epilepsy. Neurology. 1993;43:1998-2006.

47. Koepp MJ, Hammers A, Labbe C, Woermann FG, Brooks DJ, Duncan JS. ${ }^{11}$ Cflumazenil PET in patients with refractory temporal lobe epilepsy and normal MRI. Neurology. 2000;54:332-339.

48. Muzik O, da Silva EA, Juhasz C, et al. Intracranial EEG versus flumazenil and glucose PET in children with extratemporal lobe epilepsy. Neurology. 2000; 54:171-179.

49. Savic I, Thorell JO, Roland P. $\left[{ }^{11} \mathrm{C}\right]$ flumazenil positron emission tomography visualizes frontal epileptogenic regions. Epilepsia. 1995;36:1225-1232.

50. Juhász C, Chugani DC, Muzik O, et al. Relationship of flumazenil and glucose PET abnormalities to neocortical epilepsy surgery outcome. Neurology. 2001;56: 1650-1658.

51. Richardson MP, Friston KJ, Sisodiya SM, et al. Cortical grey matter and benzodiazepine receptors in malformations of cortical development: a voxel-based comparison of structural and functional imaging data. Brain. 1997;120:1961-1973.

52. Hammers A, Koepp MJ, Hurlemann R, et al. Abnormalities of grey and white matter $\left[{ }^{11} \mathrm{C}\right]$ flumazenil binding in temporal lobe epilepsy with normal MRI. Brain. 2002;125:2257-2271.

53. Natsume J, Kumakura Y, Bernasconi N, et al. Alpha- $\left[{ }^{11} \mathrm{C}\right]$ methyl-L-tryptophan and glucose metabolism in patients with temporal lobe epilepsy. Neurology. 2003;60:756-761.

54. Chugani HT, Kumar A, Kupsky W, Asano E, Sood S, Juhasz C. Clinical and histopathologic correlates of ${ }^{11} \mathrm{C}$-alpha-methyl-L-tryptophan (AMT) PET abnormalities in children with intractable epilepsy. Epilepsia. 2011;52:1692-1698.

55. Frost JJ, Mayberg HS, Fisher RS, et al. Mu-opiate receptors measured by positron emission tomography are increased in temporal lobe epilepsy. Ann Neurol. 1988;23:231-237.

56. Mayberg HS, Sadzot B, Meltzer CC, et al. Quantification of mu and non-mu opiate receptors in temporal lobe epilepsy using positron emission tomography. Ann Neurol. 1991;30:3-11.

57. Koepp MJ, Richardson MP, Brooks DJ, Duncan JS. Focal cortical release of endogenous opioids during reading-induced seizures. Lancet. 1998;352:952-955.

58. Kumlien E, Hilton-Brown P, Spannare B, Gillberg PG. In vitro quantitative autoradiography of $\left[{ }^{3} \mathrm{H}\right]$-L-deprenyl and $\left[{ }^{3} \mathrm{H}\right]-\mathrm{PK} 11195$ binding sites in human epileptic hippocampus. Epilepsia. 1992;33:610-617.

59. Kumlien E, Nilsson A, Hagberg G, Langstrom B, Bergstrom M. PET with ${ }^{11} \mathrm{C}$ deuterium-deprenyl and ${ }^{18} \mathrm{~F}-\mathrm{FDG}$ in focal epilepsy. Acta Neurol Scand. 2001;103:360-366.

60. Werhahn KJ, Landvogt C, Klimpe S, et al. Decreased dopamine D2/D3-receptor binding in temporal lobe epilepsy: an $\left[{ }^{18} \mathrm{~F}\right]$ fallypride PET study. Epilepsia. 2006;47:1392-1396.

61. Langer O, Bauer M, Hammers A, et al. Pharmacoresistance in epilepsy: a pilot PET study with the P-glycoprotein substrate R- $\left[{ }^{11} \mathrm{C}\right]$ verapamil. Epilepsia. 2007;48:1774-1784.
62. Kumlien E, Hartvig P, Valind S, Oye I, Tedroff J, Langstrom B. NMDA-receptor activity visualized with $(\mathrm{S})$-[N-methyl- $\left.{ }^{11} \mathrm{C}\right]$ ketamine and positron emission tomography in patients with medial temporal lobe epilepsy. Epilepsia. 1999;40:30-37.

63. Iinuma K, Yokoyama H, Otsuki T, et al. Histamine H1 receptors in complex partial seizures [letter]. Lancet. 1993;341:238.

64. Fedi M, Berkovic SF, Scheffer IE, et al. Reduced striatal D1 receptor binding in autosomal dominant nocturnal frontal lobe epilepsy. Neurology. 2008;71:795798.

65. Picard F, Bruel D, Servent D, et al. Alteration of the in vivo nicotinic receptor density in ADNFLE patients: a PET study. Brain. 2006;129:20472060 .

66. Hirvonen J, Kreisl WC, Fujita M, et al. Increased in vivo expression of an inflammatory marker in temporal lobe epilepsy. J Nucl Med. 2012;53:234240 .

67. Kaminska A, Chiron C, Ville D, et al. Ictal SPECT in children with epilepsy: comparison with intracranial EEG and relation to postsurgical outcome. Brain. $2003 ; 126: 248-260$

68. Lee JJ, Kang WJ, Lee DS, et al. Diagnostic performance of ${ }^{18}$ F-FDG PET and ictal ${ }^{99 \mathrm{~m} T c-H M P A O ~ S P E T ~ i n ~ p e d i a t r i c ~ t e m p o r a l ~ l o b e ~ e p i l e p s y: ~ q u a n t i t a t i v e ~ a n a l-~}$ ysis by statistical parametric mapping, statistical probabilistic anatomical map, and subtraction ictal SPET. Seizure. 2005;14:213-220.

69. Véra P, Kaminska A, Cieuta C, et al. Use of subtraction ictal SPECT co-registered to MRI for optimizing the localization of seizure foci in children. $\mathrm{J} \mathrm{Nucl}$ Med. 1999;40:786-792.

70. Benifla M, Otsubo H, Ochi A, et al. Temporal lobe surgery for intractable epilepsy in children: an analysis of outcomes in 126 children. Neurosurgery. 2006;59:1203-1213.

71. Harvey AS, Bowe JM, Hopkins IJ, Shield LK, Cook DJ, Berkovic SF. Ictal ${ }^{99 \mathrm{~m}} \mathrm{Tc}-\mathrm{HMPAO}$ single photon emission computed tomography in children with temporal lobe epilepsy. Epilepsia. 1993;34:869-877.

72. Rowe CC, Berkovic SF, Austin MC, McKay WJ, Bladin PF. Patterns of postictal cerebral blood flow in temporal lobe epilepsy: qualitative and quantitative analysis. Neurology. 1991;41:1096-1103.

73. Chiron C, Vera P, Kaminska A, et al. Rev Neurol (Paris). 1999;155:477-481.

74. O'Brien TJ, So EL, Mullan BP, et al. Subtraction SPECT co-registered to MRI improves postictal SPECT localization of seizure foci. Neurology. 1999;52:137146.

75. Weil S, Noachtar S, Arnold S, Yousry TA, Winkler PA, Tatsch K. Ictal ECDSPECT differentiates between temporal and extratemporal epilepsy: confirmation by excellent postoperative seizure control. Nucl Med Commun. 2001;22: 233-237.

76. Seo JH, Holland K, Rose D, et al. Multimodality imaging in the surgical treatment of children with nonlesional epilepsy. Neurology. 2011;76:41-48.

77. Sturm JW, Newton MR, Chinvarun Y, Berlangieri SU, Berkovic SF. Ictal SPECT and interictal PET in the localization of occipital lobe epilepsy. Epilepsia. 2000;41:463-466.

78. Kim SK, Lee DS, Lee SK, et al. Diagnostic performance of $\left[{ }^{18} \mathrm{~F}\right]$ FDG-PET and ictal [ ${ }^{99 \mathrm{~m} T \mathrm{~T}]-H M P A O ~ S P E C T}$ in occipital lobe epilepsy. Epilepsia. 2001;42: 1531-1540. 